\title{
Split hand phenomenon: An early marker for amyotrophic lateral sclerosis
}

\author{
Javier A. Galnares-Olalde ${ }^{1}$, Juan C. López-Hernández ${ }^{2 *}$, Jorge de Saráchaga-Adib", \\ Roberto Cervantes-Uribe ${ }^{2}$, and Edwin S. Vargas-Cañas ${ }^{2}$ \\ ${ }^{1}$ Department of Neurology, Instituto Nacional de Neurología y Neurocirugía Manuel Velasco Suárez, Mexico City, Mexico; ${ }^{2}$ Department of \\ Neuromuscular Disease, Instituto Nacional de Neurología y Neurocirugía Manuel Velasco Suárez, Mexico City, Mexico
}

\begin{abstract}
Background: Amyotrophic lateral sclerosis (ALS) is a progressive disease characterized by degeneration of upper and lower motor neurons. Time from symptom onset to confirmed diagnosis has been reported from 8 to 15 months in ALS. Objectives: To describe the frequency of the split hand phenomenon and propose it as an early biomarker for ALS diagnosis. Methods: A retrospective, analytical, descriptive, and single-center observational study was performed. The split hand ratio was determined by dividing distal abductor pollicis brevis/abductor digit minimi compound muscle action potentials; a result < 0.6 was considered present. Results: Fifty-four patients with ALS diagnosis were included in the study. The split hand ratio was identified in $61.5 \%$ of patients with definite ALS, in $68.7 \%$ with probable $A L S, 80 \%$ with possible $A L S$, and in $50 \%$ with suspected ALS. The split hand phenomenon was identified in $60 \%$ of patients within 12 months of symptom onset. Conclusion: We provide evidence for an additional neurophysiological tool that helps early diagnosis of ALS.
\end{abstract}

Key words: Amyotrophic lateral sclerosis. Motor neuron disease. Split hand phenomenon. El Escorial criteria.

\section{Fenómeno de mano dividida: Un marcador temprano de esclerosis lateral amiotrófica}

\section{Resumen}

Antecedentes: La esclerosis lateral amiotrófica (ELA) es una enfermedad progresiva caracterizada por la degeneración de las neuronas motoras superiores e inferiores. Se ha reportado que el tiempo desde el inicio de los síntomas hasta el diagnóstico confirmado es de 8 a 15 meses. Objetivo: Describir la frecuencia del fenómeno de mano dividida en las etapas iniciales de la enfermedad y proponerlo como un marcador temprano para el diagnóstico. Métodos: se realizó un estudio observacional retrospectivo, analítico, descriptivo y unicéntrico. La relación de mano dividida se determinó dividiendo los potenciales de acción compuestos motores distales entre abductor pollicis brevis/abductor digit minimi (APB/ADM); se consideró presente un resultado <0.6. Resultados: Se incluyeron cincuenta y cuatro pacientes con diagnóstico de ELA. EI fenómeno de mano dividida se identificó en el $61.5 \%$ de los pacientes con ELA definida, en el $68.7 \%$ con ELA probable, el $80 \%$ con ELA posible y en el 50\% con sospecha de ELA. El fenómeno de la mano dividida se identificó en el $60 \%$ de los pacientes dentro de los primeros 12 meses tras el inicio de síntomas. Conclusión: Proporcionamos evidencia para una herramienta neurofisiológica en la ayuda del diagnóstico temprano de ELA.

Palabras clave: Esclerosis lateral amiotrófica. Enfermedad de la motoneurona. Fenómeno de mano dividida. El Escorial criteria.

\section{Correspondence:}

*Steven Vargas-Cañas

E-mail: clinicaneuromuscular.innn@gmail.com

2604-6180/ ( 2021 Academia Mexicana de Neurolo 2604-6180/ ๔ 2021 Academia Mexicana de Neurología A.C. Published by Permanyer. This is an open access article under the CC BY-NC-ND license
(http://creativecommons.org/licenses/by-nc-nd/4.0/).

Date of reception: 27-12-2020

Date of acceptance: 16-03-2021

DOI: $10.24875 / R M N .20000135$
Available online: 07-07-2021

Rev Mex Neuroci. 2021;22(4):141-145 www.revmexneurociencia.com 


\section{Introduction}

Amyotrophic lateral sclerosis (ALS) is a progressive disease characterized by degeneration of upper motor neurons (UMNs) and lower motor neurons (LMNs), leading to gradual weakness that affects bulbar, cervi$\mathrm{cal}$, thoracic, and lumbar muscles ${ }^{1}$. Diagnosis is based on clinical and neurophysiological findings, and currently, there are no biomarkers or additional tools to rely ${ }^{2}{ }^{2}$. To date, pathophysiological mechanisms are not fully understood, however, it is widely assumed that ALS is the result of an interaction between genetic and environmental factors ${ }^{3}$.

Time from symptom onset to confirmed diagnosis has been reported from 8 to 15 months in $\mathrm{ALS}^{4}$. About half of patients receive at least one alternative diagnosis before diagnostic confirmation. This delay in diagnosis represents a missed opportunity to prompt research and address the patient's symptoms ${ }^{5}$.

The split hand sign denotes localized weakness and wasting of the abductor pollicis brevis (APB) and first dorsal interosseous (FDI) muscles with relative sparing of the abductor digit minimi (ADM) ${ }^{6}$. In nerve conduction studies (NCSs), a decreased APB/ADM compound muscle action potential (CMAP) amplitude ratio $(<0.6)$ reflects the split hand phenomenon, which in ALS indicates cortical motor neuron compromise, particularly because APB and FDI are muscles with extensive corticospinal connections affected by glutamate excitotoxicity ${ }^{7}$. The split hand phenomenon is observed in $55 \%$ of ALS patients. The dissociated hand muscle atrophy, particularly the combination of $\mathrm{APB} / \mathrm{ADM}$ ratio $<0.6$ and FDI/ADM ratio $<0.9$, is rarely found in pure LMN disease, cervical spondylotic amyotrophy, and polyneuropathies ${ }^{8}$. As few data exist on split hand ratio in patients with ALS, we aim to describe the frequency of this phenomenon in the early stages of the disease.

\section{Methods}

A retrospective, analytical, descriptive, and single-center observational study was performed in the period from January 2017 to December 2019. Patients diagnosed with any degree of certainty of ALS (suspected, possible, probable, and definitive) by "El Escorial" were included in the study. ALS patients aged at least 18 years with complete NCSs were enrolled. Patients with incomplete medical records were excluded, as well as those with cervical spondylotic myelopathy, peripheral neuropathies, and pure LMN disease.
NCSs were performed by a neurophysiologist with extensive experience in neuromuscular diseases. The distal CMAP $(\mathrm{mV})$ recordings were obtained from the median (stimulating in the elbow with recording in the APB muscle) and ulnar nerves (stimulating in the elbow with recording in the adductor digiti minimi muscle). The split hand ratio was determined by dividing distal APB/ ADM CMAPs; a result < 0.6 was considered present.

We defined ALS stages according to time. Early-stage ALS was defined as $<12$ months since symptom onset. On the other hand, late stage was considered if symptoms have more than 12 months.

\section{Statistical analysis}

For descriptive analysis, data distribution was determined with Kolmogorov-Smirnov test. Variables were described as mean, \pm standard deviation, or median and interquartile range according to distribution. Categorical variables were described in frequencies and percentages. The ANOVA test for continuous parametric variables was used to search for differences between groups. Mann-Whitney U-test was used for non-parametric continuous variables, as well as the Chi-square test and Fisher's exact test for categorical variables. $p \leq 0.05$ was considered statistically significant.

\section{Results}

Fifty-four patients with ALS diagnosis were included in the study. About $52 \%$ were men and the mean age at diagnosis was $52.8 \pm 11.4$ years. Median time from symptom onset to diagnosis was 24 months. Considering the different degrees of diagnostic certainty of ALS according to the El Escorial criteria, $48.1 \%$ fulfilled criteria for defined ALS, $29.6 \%$ for probable ALS, $18.5 \%$ for possible ALS, and $3.6 \%$ for suspected ALS. Patients with definite, probable, and possible ALS had a shorter time from symptom onset to diagnosis with a mean of 24 months, compared to 60 months in the suspected ALS group (Table 1). Patients with definite, probable, and possible ALS had earlier NCS performed, contrarily to those with suspected ALS (55.5 months).

The split hand ratio could not be calculated in $5 \%$ of patients due to unexcitable nerves. The split hand phenomenon was identified in $70 \%$ of ALS patients. Regarding the degree of certainty of the El Escorial criteria, the split hand ratio was identified in $61.5 \%$ of patients with definite ALS, in $68.7 \%$ with probable ALS, 
Table 1. Demographics and nerve conduction studies across El Escorial degrees of certainty

\begin{tabular}{|c|c|c|c|c|c|}
\hline & Definite ( $n=26$ ) & Probable $(n=16)$ & Possible $(n=10)$ & Suspected ( $=2$ ) & $\mathrm{p}$ value \\
\hline Age - year & $54.1 \pm 10.2$ & $52.1 \pm 12.3$ & $50.4 \pm 14.4$ & $55.5 \pm 2.1$ & 0.82 \\
\hline Male gender - $\mathrm{n}(\%)$ & $11(42.3)$ & $9(56.2)$ & $6(60)$ & $1(50)$ & 0.73 \\
\hline $\begin{array}{l}\text { Time from symptom onset to } \\
\text { diagnosis - months, median (IOR) }\end{array}$ & $24(12-61.2)$ & $24(13-48)$ & $24(24-72)$ & $60(24-60)$ & 0.24 \\
\hline \multicolumn{6}{|l|}{ Neurophysiologic findings } \\
\hline $\begin{array}{l}\text { Time from symptom onset to } \\
\text { neurophysiology study - months, } \\
\text { median (IQR }\end{array}$ & $24(12-45)$ & $24(12-42)$ & $30(22.5-72)$ & $55.5(15-55.5)$ & 0.48 \\
\hline Distal CMAP, median nerve & $2.6 \pm 2.7$ & $3.6 \pm 2.9$ & $4.8 \pm 3.1$ & $8.4 \pm 2.1$ & 0.025 \\
\hline Distal CMAP cubital nerve & $4.0 \pm 2.8$ & $5.2 \pm 3.0$ & $8.3 \pm 3.9$ & $10.9 \pm 0.28$ & 0.004 \\
\hline APB/ADM ratio & $0.89 \pm 0.98$ & $0.61 \pm 0.45$ & $0.56 \pm 0.24$ & $0.77 \pm 0.22$ & 0.54 \\
\hline Split hand phenomenon - $\mathrm{n}(\%)$ & $16(61.5)$ & $11(68.7)$ & $8(80)$ & $1(50)$ & 0.80 \\
\hline
\end{tabular}

APB: abductor pollicis brevis; ADM: abductor digiti minimi; IQR: interquartile range; CMAP: compound muscle action potential.

Table 2. Split hand ratio and nerve conduction studies across ALS symptomatic stages

\begin{tabular}{|l|c|c|c|c|}
\hline & $\leq \mathbf{1 2}$ months $(\mathbf{n}=\mathbf{1 0})$ & $\mathbf{1 2 - 2 4}$ months $(\mathbf{n}=\mathbf{2 3})$ & $\geq \mathbf{2 4}$ months $(\mathbf{n}=\mathbf{1 8})$ & $\mathbf{p}$ value \\
\hline Split hand phenomenon, $\mathrm{n}(\%)$ & $6(60)$ & $16(69.5)$ & $13(72.2)$ & 0.79 \\
\hline APB/ADM ratio & $0.61 \pm 0.35$ & $0.76 \pm 0.51$ & $0.76 \pm 1.0$ & 0.80 \\
\hline Distal CMAP, median nerve $(\mathrm{mV})$ & $3.2 \pm 2.8$ & $4.4 \pm 3.5$ & $2.8 \pm 2.5$ & 0.23 \\
\hline Distal CMAP, ulnar nerve $(\mathrm{mV})$ & $5.6 \pm 4.0$ & $5.8 \pm 3.9$ & $5.0 \pm 4.1$ & 0.75 \\
\hline
\end{tabular}

APB: abductor pollicis brevis; ADM: abductor digiti minimi; ALS: amyotrophic lateral sclerosis, IQR: interquartile range; CMAP: compound muscle action potential.

$80 \%$ with possible ALS, and in $50 \%$ with suspected ALS (Table 1).

Moreover, the split hand phenomenon was identified in $60 \%$ of patients within 12 months of symptom onset, $69.5 \%$ between 12 and 24 months, and $72.2 \%$ after 25 months (Table 2). An example of the split hand sign with further decreased APB/ADM ratio (split hand phenomenon) is shown in figure 1.

\section{Discussion}

Epidemiological studies report an ALS male incidence of $3 / 100,000$ inhabitants/year compared to a female incidence of 2.4/100,000 inhabitants/year, with a 1.5:1 ratio. This relationship was not observed in our study since there were 28 men and 26 women, with a 1:1 ratio. About $90 \%$ of ALS cases occur sporadically, while $10 \%$ are familiar ${ }^{9,10}$. None of our patients had ALS family history. The mean age at diagnosis in our study is $52.8 \pm 11.4$ years, which is similar to world reports, with only $5 \%$ of the patients presenting before the age of $30^{10}$.

Early ALS diagnosis represents a diagnostic challenge when signs and symptoms are not so evident. Therefore, diagnosis at symptom onset is usually delayed in ALS. In our study, we identified that time to diagnosis from symptom onset is 24 months, conversely to what other authors have reported in a range from 8 to 15 months ${ }^{4}$. This might be explained due to a delay in referral time to our center.

ALS diagnosis is defined by El Escorial criteria, which encompasses clinical findings of UMN and LMN. Definite diagnosis includes clinical evidence of UMN and LMN signs in bulbar plus two spinal regions, or three spinal regions ${ }^{11}$. Nonetheless, they do not consider electrophysiologic findings, which may identify earlier 


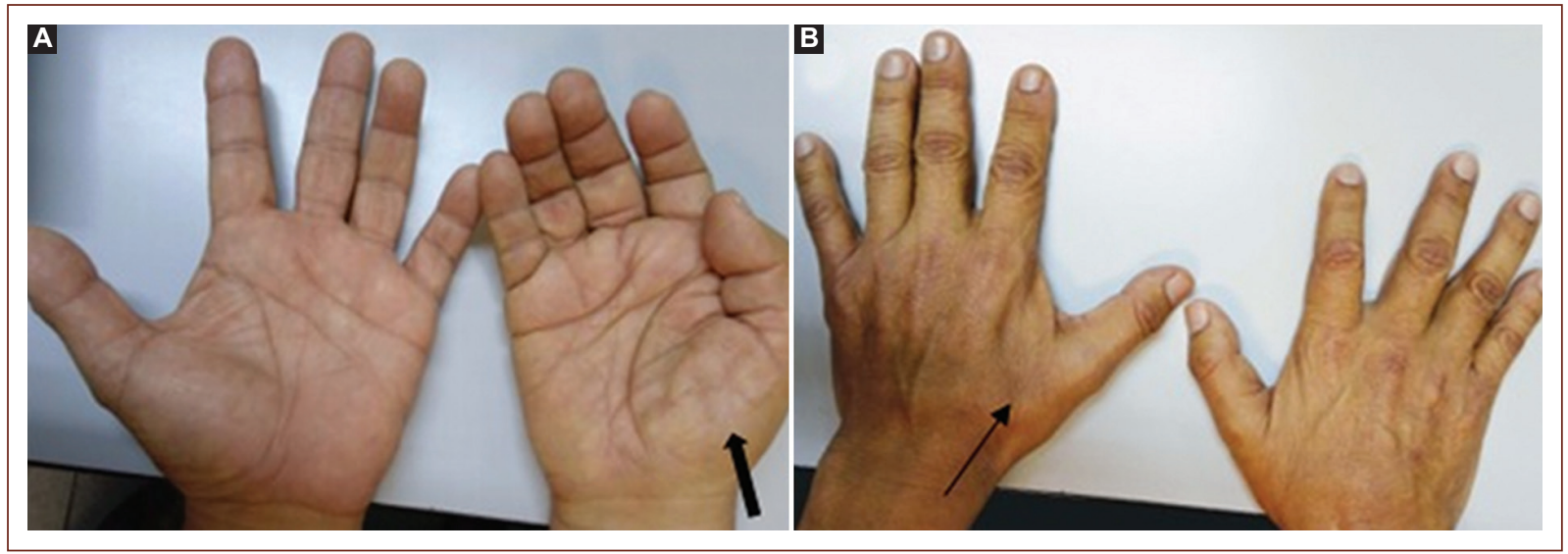

Figure 1. A 65-year-old man with definite ALS diagnosis, who started with the right hand weakness. A: Thenar atrophy in the right hand. B: First interosseous atrophy of the left hand. CMAP distal APB/ADM ratio was 0.45 , consistent with the split hand phenomenon. ALS: amyotrophic lateral sclerosis; CMAP: compound muscle action potential, APB: abductor pollicis brevis; ADM: abductor digiti minimi.

signs of UMN and LMN that are not evident in clinical examination. On the other hand, newer diagnostic criteria such as the Awaji-Jima criteria include both NCS and El Escorial clinical examination, increasing both sensitivity and specificity ${ }^{12}$. Unfortunately, neither El Escorial nor Awaji-Jima considers any early biomarkers. Electrophysiological findings may play an important role in early diagnosis, as some signs may be identified in neurophysiology but not in clinical examination when the disease is in early stages. Other markers as well have been identified as potential early biomarkers such as motor band sign on magnetic resonance imaging (MRI), bright tongue on MRI, pyramidal tract tractography (DTI-MRI), motor evoked potentials by transcranial magnetic stimulation, and cytokine detection in cerebrospinal fluid.

Recently, a group of experts proposed a new definition of ALS in patients with the presence of UMN and LMN dysfunction in at least one body region as well as progressive motor impairment preceded by normal motor function ${ }^{13}$. We consider these as promising criteria for early diagnosis as they consider only UMN and LMN findings in one segment to make the diagnosis, additional to NCS results. Despite no specific curable treatment exists for ALS, early diagnosis has been shown to improve quality of life as multidisciplinary management is promptly implemented ${ }^{1,2}$. Limited information exists regarding UMN dysfunction in electrophysiological studies. Some authors consider F-wave persistence as an indirect marker of UMN compromise. Transcranial magnetic stimulation has been suggested as a marker, however, it requires standardization and is not available in most countries ${ }^{14}$.

The split hand phenomenon is defined as decreased APB/ADM CMAP amplitude ratio $(<0.6)$. This finding implies a greater compromise of thenar compared to hypothenar muscles. Even though both regions are innervated by C8-T1 roots, APB and FDI are muscles with extensive corticospinal connections that are easily affected by glutamate excitotoxicity ${ }^{6}$. Kuwabara et al. reported in a multicenter study that decreased APB/ADM ratio was found in $41 \%$ of ALS patients and in $5 \%$ of normal controls, which is close related to our findings. They concluded that prominent muscle atrophy in APB and FDI, with relatively preserved ADM, appears to be specific to $\mathrm{ALS}^{7}$. In contrast, our overall prevalence of split hand phenomenon in ALS patients was 70\%.

Despite controversies on this subject ${ }^{15}$, the authors hereby consider the split hand ratio as an UMN finding, commonly found in ALS and extremely rare in healthy subjects ${ }^{7}$. Furthermore, the split hand phenomenon's prevalence appears to be greater in early ALS stages and less prevalent when muscle atrophy increases. About $60 \%$ of patients presented the split hand phenomenon within 12 months of symptom onset. No significant differences in prevalence of split hand ratio were observed between early and late ALS. This is an important finding as this may provide a marker for supportive ALS diagnosis in early stages.

Clinicians must be careful as a reduced split hand ratio may be observed in other motor neuronopathies, such as remote polio, monomyelic amyotrophy, or spinal muscular 
atrophy, although dissociated small muscle atrophy is most frequently seen in $\mathrm{ALS}^{6}$. Limitations of the present study include the small number of patients and the retrospective character. Other limitation was that data collection was performed during routine clinical practice.

\section{Conclusion}

The split hand phenomenon is commonly found across all different degrees of certainty of El Escorial clinical diagnostic criteria. Similarly, it is also commonly encountered in the early stages of the disease. We provide evidence for a neurophysiological tool in the aid of early diagnosis of ALS. This should serve as background for further studies to identify early neurophysiologic markers in this disease. Our findings could improve diagnostic yield in the forthcoming studies and provide clinical and paraclinical biomarkers in this incurable disease.

\section{Funding}

None to declare.

\section{Conflicts of interest}

The authors declare no conflicts of interest.

\section{Ethical disclosures}

Protection of human and animal subjects. The authors declare that no experiments were performed on humans or animals for this study.

Confidentiality of data. The authors declare that they have followed the protocols of their work center on the publication of patient data.
Right to privacy and informed consent. The authors declare that no patient data appear in this article.

\section{References}

1. Hardiman O, Al-Chalabi A, Chio A, Corr EM, Logroscino G, Robberecht W, et al. Amyotrophic lateral sclerosis. Nat Rev. 2017;3:17071.

2. Kiernan M, Vucic V, Cheah B, Turner MR, Eisen A, Hardiman O, et al. Amyotrophic lateral sclerosis. Lancet. 2011;377:942-55.

3. Oskarsson B, Gendron TF, Staff NP. Amyotrophic lateral sclerosis: an update for 2018. Mayo Clin Proc 2018;93:1617-28.

4. Mitchell JD, Callagher P, Gardham J, Mitchell C, Dixon M, Addison-Jones R, et al. Timelines in the diagnostic evaluation of people with suspected amyotrophic lateral sclerosis (ALS)/motor neuron disease (MND)-a 20-year review: can we do better? Amyotroph Lateral Scler. 2010;11:537-41.

5. Paganoni S, Macklin EA, Lee A, Murphy A, Chang J, Zipf A, et al. Diagnostic timelines and delays in diagnosing amyotrophic lateral sclerosis (ALS). Amyotroph Lateral Scler Frontotemporal Degener. 2014;15:453-6.

6. Eisen A, Kuwabara S. The split hand syndrome in amyotrophic lateral sclerosis. J Neurol Neurosurg Psychiatry 2012;83:399-403.

7. Kuwabara S, Sonoo M, Komori T, Shimizu T, Hirashima F, Inaba A, et al. Dissociated small hand muscle atrophy in amyotrophic lateral sclerosis: frequency, extent, and specificity. Muscle Nerve 2008;37:426-30

8. Wang ZL, Cui L, Liu M, Zhang K, Liu S, Ding Q. Split-hand syndrome in amyotrophic lateral sclerosis: differences in dysfunction of the FDI and ADM spinal motoneurons. Front Neurosci. 2019;13:371.

9. Chiò A, Logroscino G, Traynor BJ, Collins J, Simeone JC, Goldstein LA, et al. Global epidemiology of amyotrophic lateral sclerosis: a systematic review of the published literature. Neuroepidemiology. 2013;41:118-30.

10. Logroscino G, Traynor BJ, Hardiman O, Chiò A, Mitchell D, Swingler RJ, et al. Incidence of amyotrophic lateral sclerosis in Europe. J Neurol Neurosurg Psychiatry. 2010;81:385-90.

11. Brooks BR. El Escorial world federation of neurology criteria for the diagnosis of amyotrophic lateral sclerosis. Subcommittee on motor neuron diseases/amyotrophic lateral sclerosis of the world federation of neurology research group on neuromuscular diseases and the El Escorial "clinical limits of amyotrophic lateral sclerosis" workshop contributors. J Neurol Sci. 1994;124 Suppl:96-107.

12. Costa J, Swash M, de Carvalho M. Awaji criteria for the diagnosis of amyotrophic lateral sclerosis: a systematic review. Arch Neurol. 2012;69:1410-6.

13. Shefner JM, Al-Chalabi A, Baker MR, Cui LY, de Carvalho M, Eisen A, et al. A proposal for new diagnostic criteria for ALS. Clin Neurophysiol. 2020;131:1975-8.

14. Eisen A, Braak H, Del Tredici K, Lemon R, Ludolph AC, Kiernan MC. Cortical influences drive amyotrophic lateral sclerosis. J Neurol Neurosurg Psychiatry. 2017;88:917-24.

15. Kim JE, Hong YH, Lee JH, Ahn SW, Kim SM, Park KS, et al. Pattern difference of dissociated hand muscle atrophy in amyotrophic lateral sclerosis and variants. Muscle Nerve. 2015;51:333-7. 